Article

www.mdpi.com/journal/molecules

\title{
In Vitro Activity of Plant Extracts and Alkaloids against Clinical Isolates of Extended-Spectrum $\beta$-Lactamase (ESBL)-Producing Strains
}

\author{
Guo-Ying Zuo ${ }^{1, *}$, Fan-Yan Meng ${ }^{1,2}$, Jun Han ${ }^{3}$, Xiao-Yan Hao ${ }^{2, *}$, Gen-Chun Wang ${ }^{1}$, \\ Yun-Ling Zhang ${ }^{1}$ and Qing Zhang ${ }^{1}$
}

1 Research Center for Natural Medicines, Kunming General Hospital, PLA, Kunming 650032, China; E-Mails: zhangyunling@126.com (Y.-L.Z.); kmz@263.net (Q.Z.)

2 School of Pharmacy, Guiyang Medical College, Guiyang 550004, China; E-Mail: mfy_0@163.com (F.-Y.M.)

3 School of Basic Medicine, Yunnan Traditional Chinese Medical College, Kunming 650500, China; E-Mail: hanzjn@126.com (J.H.)

* Authors to whom correspondence should be addressed; E-Mails: zuogouiyng@263.net (G.-Y.Z); haoxiaoyan@vip.163.com (X.-Y.H); Tel.: +86-871-4774941; Fax: +86-871-4774941 (G.-Y.Z).

Received: 23 May 2011; in revised form: 12 June 2011 / Accepted: 13 June 2011 /

Published: 28 June 2011

\begin{abstract}
The antibacterial activity of $80 \%$ ethanol extracts of 10 medicinal plants collected in Yunnan (Southwest China), was tested against clinical isolates of extendedspectrum $\beta$-lactamase (ESBL)-producing strains. Their MIC values ranged between $1.56-12.50 \mathrm{mg} / \mathrm{mL}$. The most active plant extract was Chelidonium majus L. $(\mathrm{MIC}=1.56 \mathrm{mg} / \mathrm{mL})$. Two potent isoquinoline alkaloids, 8-hydroxydihydrosanguinarine and 8-hydroxydihydrochelerythrine, were identified as the major active principles through bioassay-guided fractionation and identification of the active ethyl acetate fraction from C. majus, with minimum MIC/MBC values of $15.63 / 62.50 \mu \mathrm{g} / \mathrm{mL}$.
\end{abstract}

Keywords: antibacterial plant extracts; ESBLs; 8-hydroxydihydrosanguinarine; 8-hydroxydihydrochelerythrine 


\section{Introduction}

Extended-spectrum $\beta$-lactamases (ESBLs) are enzymes produced in some Gram-negative bacilli that mediate resistance to extended-spectrum antibiotics like cephalosporin and aztreonam. The first clinical isolates expressing acquired ESBLs were identified in Germany in 1983 [1]. ESBLs have the ability to hydrolyse and cause resistance to various types of the newer $\beta$-lactam antibiotics, including the expanded-spectrum (or third-generation) cephalosporins (e.g., cefotaxime, ceftriaxone, ceftazidime) and monobactams (e.g., aztreonam), but not the cephamycins (e.g., cefoxitin and cefotetan) and carbapenems (e.g., imipenem, meropenem, and ertapenem). They are most common in clinical isolates of Escherichia coli and Klebsiella pneumoniae of the Enterobacteriaceae. The ESBL-producing multidrug-resistant (MDR) pathogens are the result of the selective pressure of currently used antibiotics and have been well recognized as a global nosocomial problem in recent years [2]. As plants can produce antimicrobial compounds to protect themselves from biotic attack, the search for antibacterial agents with different chemical structure and biological mode of action from plant sources is an alternative option in the fight against these microbes [3-5].

In the course of screening for active plant products against MDR bacteria, we paid special attention to the effects of Chinese medicinal plants on clinical isolates of ESBL-producing microorganisms. Here, we report the activities of ten plant extracts and two potent isoquinoline alkaloids 8-hydroxydihydrosanguinarine $(\mathrm{hhS}, 1)$ and 8-hydroxydihydrochelerythrine $(\mathrm{hhC}, 2)$, obtained through bioassay-guided fractionation and identification from one of the active extracts of Chelidonium majus L. (bai-qu-cai in Chinese, [6]).

\section{Results and Discussion}

As shown in Table 1, various potencies against MDR and the ATCC control of E. coli were demonstrated by the tested extracts, with inhibitory zone diameters (IZDs) of 11.0-21.0 mm and MIC values of $1.56-12.50 \mathrm{mg} / \mathrm{mL}$, respectively. Most of the extracts were active not only against MDR but also non-MDR strains of $E$. coli, which suggested the different mechanisms of effect and their potentials as alternative sources for combating the increasingly troublesome problem of bacterial infections in hospitals [2].

Bioassay-guided fractionation and isolation of an active extract from C. majus led to the identification of the 8-hydroxylated benzo[c]phenanthridine alkaloids hhS and hhC as the major active compounds. They showed potent activity against both clinical MDR isolates and ATCC control strains of E. coli, with the low MIC of $15.63 \mu \mathrm{g} / \mathrm{mL}$ (Figure 1 and Table 2). Other compounds in the active extracts are under investigation.

From the results in Table 2, it is noted that though they were both phenotypic confirmatory ESBL-producing strains, the activity of hhS and hhC against such strains from E. coli were general much more active than those from K. pneumoniae. This could be attributed to the different resistance profiles of the two bacterial species with different genotypes [1,2]. 
Table 1. IZD $(\mathrm{mm})$ and MIC $(\mathrm{mg} / \mathrm{mL})$ of the crude extracts and active fractions against selected strains.

\begin{tabular}{|c|c|c|c|c|c|c|c|c|}
\hline \multirow{2}{*}{ No. } & \multirow{2}{*}{ Species } & \multirow{2}{*}{ Family } & \multirow{2}{*}{$\begin{array}{l}\text { Speciesmen } \\
\text { number }\end{array}$} & \multirow{2}{*}{ Part $^{\text {a }}$} & \multicolumn{2}{|l|}{$E c^{b}$} & \multicolumn{2}{|c|}{ Ec-MDR $^{\mathrm{c}}$} \\
\hline & & & & & IZD & MIC & IZD & MIC \\
\hline 1 & Chelidonium majus L. & Papaveraceae & KUN201236 & $\mathrm{Wp}$ & 20.0 & 1.56 & 15.0 & 3.12 \\
\hline 2 & $\begin{array}{l}\text { Galla Chinensis } \\
\text { (Rhus chinensis) }\end{array}$ & Anacardiaceae & KUN61317 & W & 16.0 & 3.12 & 13.0 & 6.25 \\
\hline 3 & $\begin{array}{l}\text { Macleaya cordata } \\
\text { (Willd.) R. Br. } \\
\text { Medinilla }\end{array}$ & Papaveraceae & KUN201093 & Ap & 21.0 & 3.12 & 14.0 & 3.12 \\
\hline 4 & $\begin{array}{l}\text { luchuenensis C. Y. } \\
\text { Wu et C. Chen }\end{array}$ & Melastomataceae & KUN372 & $\mathrm{R}$ & 13.0 & 3.12 & 11.0 & 6.25 \\
\hline 5 & $\begin{array}{l}\text { Michelia chapaensis } \\
\text { Dandy }\end{array}$ & Magnoliaceae & KUN12152 & $\mathrm{Rh}$ & 15.0 & 3.12 & 12.0 & 6.25 \\
\hline 6 & Myrsine africana L. & Myrsinaceae & $\begin{array}{l}\text { HITBC } \\
032831\end{array}$ & Ap & 12.0 & 6.25 & 11.0 & 12.50 \\
\hline 7 & $\begin{array}{l}\text { Paeonia lactiflora } \\
\text { Pall. }\end{array}$ & Ranunculaceae & $\begin{array}{l}\text { KUN } \\
365353\end{array}$ & $\mathrm{R}$ & 16.0 & 3.12 & 13.0 & 3.12 \\
\hline 8 & $\begin{array}{l}\text { Sagentodoxa cuneata } \\
\text { (Oliv.) Rehd. et Wils. }\end{array}$ & Sagentodoxaceae & KUN3514 & $\mathrm{R}$ & 14.0 & 3.12 & 11.0 & 6.25 \\
\hline 9 & $\begin{array}{l}\text { Eurya yunnanensis } \\
\text { P.S. Hsu }\end{array}$ & Theaceae & YCP85965 & Ap & 11.0 & 12.50 & $\mathrm{NA}^{\mathrm{d}}$ & $\mathrm{NA}^{\mathrm{d}}$ \\
\hline 10 & $\begin{array}{l}\text { Viburnum foetidum } \\
\text { Will. Var. foetidum }\end{array}$ & Carprifoliaceae & KUN287 & Ap & $\mathrm{NA}^{\mathrm{d}}$ & $\mathrm{NA}^{\mathrm{d}}$ & $\mathrm{NA}^{\mathrm{d}}$ & $\mathrm{NA}^{\mathrm{d}}$ \\
\hline 11 & C. majus & Papaveraceae & KUN201236 & Fr-E & 19.0 & 1.56 & 17.0 & 3.12 \\
\hline 12 & C. majus & Papaveraceae & KUN201236 & Fr-E1 & 26.0 & 0.39 & 20.0 & 1.56 \\
\hline 13 & C. majus. & Papaveraceae & KUN201236 & Fr-E2 & 22.0 & 0.78 & 19.0 & 1.56 \\
\hline
\end{tabular}

${ }^{\mathrm{a}}$ Ap: aerial parts; F: fruits; R: roots; Rh: rhizome; Wp: whole plants; W: wart, Fr-E: ethyl acetate fraction; Fr-E1 and Fr-E2,: two sub-fractions of Fr-E; ${ }^{b}$ Ec: E. coli (ATCC25922); ${ }^{\mathrm{c}}$ Ec-MDR: A total of five selected isolates of ESBLs-producing strains were tested; ${ }^{d}$ NA: not active at concentrations up to $50 \mathrm{mg} / \mathrm{mL}$.

Figure 1. Structures of the four alkaloids (1: hhS; 2 : hhC; 3: hS; 4: hC).<smiles>[R2]Oc1c([R20])ccc2c1C([R])N(C)c1c-2ccc2cc3c(cc12)OCO3</smiles>

C. majus has a long history in Chinese and European herbal medicine [6,7] as being useful for the treatment of many diseases. The present study reveals its in vitro anti-MDR activities against clinical isolates of ESBL-producing strains for the first time as far as we are aware [7,8]. It was found that 
among the four tested alkaloids the 8-hydroxylated ones were generally more active than the nonhydroxylated alkaloids. This type of alkaloids has been previously demonstrated to possess activity against clinical isolates of methicillin-resistant Staphylococcus aureus (MRSA) and resistant clinical yeast isolates $[9,10]$. Hence, they show broad-spectrum antimicrobial properties. However, to assess the efficacy and safety of these extracts and pure compounds, further in vitro and in vivo pharmacological assays are needed.

Table 2. MICs and MBCs of the alkaloids and control agent for strains of clinical isolates.

\begin{tabular}{|c|c|c|c|c|c|c|}
\hline \multirow{2}{*}{ Strain and agent } & \multicolumn{3}{|l|}{ MIC $(\mu \mathrm{g} / \mathrm{mL})$} & \multicolumn{3}{|l|}{$\operatorname{MBC}(\mu \mathrm{g} / \mathrm{mL})$} \\
\hline & Range & $50 \%$ & $90 \%$ & Range & $50 \%$ & $90 \%$ \\
\hline \multicolumn{7}{|l|}{$E_{c-M D R}{ }^{a}$} \\
\hline $\mathrm{hhS}$ & $15.63-250.0$ & 31.25 & 125.0 & $62.50-500.0$ & 62.50 & 250.0 \\
\hline hhC & $62.50-500.0$ & 125.0 & 250.0 & $125.00-1000.0$ & 125.0 & 500.0 \\
\hline $\mathrm{hS}$ & $750.0-3000.0$ & $1500^{d}$ & $3000^{d}$ & $\mathrm{NA}^{\mathrm{d}}$ & $\mathrm{NA}^{\mathrm{d}}$ & $\mathrm{NA}^{\mathrm{d}}$ \\
\hline $\mathrm{hC}$ & $1500.0-3000.0$ & $3000^{d}$ & $3000^{d}$ & $\mathrm{NA}^{\mathrm{d}}$ & $\mathrm{NA}^{\mathrm{d}}$ & $\mathrm{NA}^{\mathrm{d}}$ \\
\hline imipenem & $0.03-0.50$ & 0.12 & 0.25 & $0.12-2.0$ & 0.25 & 0.50 \\
\hline \multicolumn{7}{|l|}{$K p-\mathrm{MDR}^{\mathrm{b}}$} \\
\hline hhS & $93.8-375.0$ & 187.5 & 375.0 & $375.0-1500.0$ & 750.0 & 1500.0 \\
\hline hhC & $187.5-750.0$ & 187.5 & 375.0 & $375.0-1500.0$ & 750.0 & 1500.0 \\
\hline $\mathrm{hS}$ & $750.0-3000.0$ & $1500^{d}$ & $3000^{d}$ & $\mathrm{NA}^{\mathrm{d}}$ & $\mathrm{NA}^{\mathrm{d}}$ & $\mathrm{NA}^{\mathrm{d}}$ \\
\hline $\mathrm{hC}$ & $1500.0-3000.0$ & $3000^{d}$ & $3000^{d}$ & $\mathrm{NA}^{\mathrm{d}}$ & $\mathrm{NA}^{\mathrm{d}}$ & $\mathrm{NA}^{\mathrm{d}}$ \\
\hline imipenem & $0.06-1.00$ & 0.25 & 0.50 & $0.12-2.0$ & 0.500 & 1.00 \\
\hline \multicolumn{7}{|l|}{$E c^{c}$} \\
\hline hhS & 15.63 & & & 31.25 & & \\
\hline hhC & 125.0 & & & 250.0 & & \\
\hline $\mathrm{hS}$ & 375.0 & & & 1500.0 & & \\
\hline $\mathrm{hC}$ & 375.0 & & & 1500.0 & & \\
\hline imipenem & 0.12 & & & 0.25 & & \\
\hline
\end{tabular}

${ }^{\mathrm{a}}$ Ec-MDR: 18 isolates of ESBLs-producing strains from E. coli; ${ }^{\mathrm{b}} \mathrm{K} p$-MDR: 12 isolates of ESBLsproducing strains from K. pneumonia; ${ }^{\mathrm{c}}$ Ec: E. coli (ATCC25922); ${ }^{\mathrm{d}} \mathrm{NA}$ : not active at concentrations up to $3000 \mu \mathrm{g} / \mathrm{mL}$.

\section{Experimental}

\subsection{Plant Material}

Ten authenticated plant materials (Table 1) were collected in the mountainous Dali and Honghe districts of Yunnan Province, China, at attitudes of 600-2,500 m in September of 2007. They were identified by Shui Yuming of t he Kunming Institute of Botany, the Chinese Academy of Science (CAS, China) where voucher specimens were deposited.

\subsection{Bacterial Strains and Culture Media}

ESBL-producing MDR strains (18 from E. coli and 12 from K. pneumoniae isolates, respectively) were obtained from the infectious samples of critically ill patients at Kunming General Hospital 
$(\mathrm{KGH})$. Pathogen purification and identification were conducted in the clinical microbiology laboratory of $\mathrm{KGH}$ following the standard procedures and the criteria of the Clinical and Laboratory Standards Institute (CLSI) [11-13]. Briefly, the isolates were initially screened using disks of ceftazidime $(30 \mu \mathrm{g})$ and aztreonam $(30 \mu \mathrm{g})$, and confirmed by using both ceftazidime and cefotaxime $(30 \mu \mathrm{g})$, alone and in combination with clavulanic acid $(10 \mu \mathrm{g})$. An isolate of a $\geq 5-\mathrm{mm}$ increase in a zone diameter for either antimicrobial agent tested in combination with clavulanic acid compared with its zone when tested alone [e.g., ceftazidime zone $=16 \mathrm{~mm}$; ceftazidime-clavulanic acid $(30 / 10 \mu \mathrm{g})$ zone $=21 \mathrm{~mm}$ ] was identified as an ESBL-producing isolate. The control strain ATCC 25922 (E. coli) was obtained from the National Institute for the Control of Pharmaceutical and Biological Products (NICPBP, China). Standard Mueller-Hinton agar and broth (MHA and MHB, Tianhe Microbial Agents Co., Hangzhou, China) were used as culture media. Imipenem (Merck \& Co., Inc.) was used as the positive control agent.

\subsection{Extract Preparation and Isolation of the Active Compounds from C. majus Extracts}

The air-dried and ground plant material (30 g) was macerated with $80 \%$ ethanol $(500 \mathrm{~mL})$ for 5 days, filtered and the mare was further macerated twice with the same solvent overnight and filtered after being sonicated for $30 \mathrm{~min}$. The filtrates were combined and the solvent was evaporated at $40{ }^{\circ} \mathrm{C}$ under vacuum. Ten extracts were prepared as a whole (Table 1).

A larger sample $(300 \mathrm{~g})$ of active extract from C. majus $(3 \mathrm{~kg})$ was suspended in $600 \mathrm{~mL}$ of sterilized and deionated water and the suspension was successively fractionated between water and petroleum ether and AcOEt, of which the AcOEt fraction (Fr-E) showed the most activity in a bioassay-guided fractionation procedure. The fraction $(25 \mathrm{~g})$ was subjected to vacuum liquid chromatography over silica gel-H (500 mesh, Qingdao Haiyang Chemical Co., Ltd. Qingdao, China) and eluted with gradients of $\mathrm{CHCl}_{3}-\mathrm{MeOH}$ to afford two active fractions (Fr-E1 and Fr-E2), which were further purified by reverse-phase HPLC column chromatography to yield the two alkaloids $\mathbf{1}$ $(15.4 \mathrm{mg})$ and $2(8.5 \mathrm{mg})$, respectively. Two other alkaloids, dihydrosanguinarine (hS, 3, $200 \mathrm{mg})$ and dihydrochelerythrine (hC, 4, $80 \mathrm{mg}$ ), were also obtained. All the spectral data were in agreement with the literature $[14,15]$. Their structures are shown in Figure 1. The MIC and MBC of the four alkaloids were determined accordingly at concentrations ranged from $0.003-3.0 \mathrm{mg} / \mathrm{mL}$ (Table 2).

\subsection{Susceptibility Test}

The ten extracts were first subjected to a susceptibility test of their IZD (mm) following the previous agar well diffusion method with a slight modification [16]. The inoculums were $1.5 \times 10^{8} \mathrm{CFU} / \mathrm{mL}$ suspensions and $70 \mu \mathrm{L}$ aliquots of the extracts $(50 \mathrm{mg} / \mathrm{mL}$ in $50 \%$ aqueous DMSO) were placed in $6 \mathrm{~mm}$ (diam.) agar wells, incubated at $35{ }^{\circ} \mathrm{C}$ for $24 \mathrm{~h}$. The MIC of the extracts (concentrations ranged from $0.5-50 \mathrm{mg} / \mathrm{mL}$ in $50 \% \mathrm{DMSO}$ ) for each organism were determined by the two-fold serial broth macro dilution method with MHB in tubes [12,16,17], with a slight modification as incubated at $35{ }^{\circ} \mathrm{C}$ for $24 \mathrm{~h}$ and each tube contained inoculums of $5 \times 10^{5} \mathrm{CFU} / \mathrm{mL}$. All experiments were carried out in triplicate with $50 \%$ aqueous DMSO as the solvent control. The results are shown in Table 1. 


\section{Conclusions}

Ten Chinese medicinal plant extracts demonstrated varying levels of activity against clinical isolates of extended-spectrum $\beta$-lactamase (ESBL)-producing strains. Four alkaloids were identified from C. majus extracts, with 8-hydroxydihydrosanguinarine and 8-hydroxydihydrochelerythrine being the most active compounds. Their clinical utility against infections of ESBLs producers warrant further pharmacological investigations.

\section{Acknowledgments}

This work was supported by a grant from the National Natural Science Foundation of China (NSFC 81073126) and the supporting fund of Yunnan Province of China (2008PY001). We are also grateful to the Kunming Institute of Botany (CAS) for spectral analysis.

\section{Conflict of Interest}

The authors declare no conflict of interest.

\section{References}

1. Gniadkowski, M. Evolution and epidemiology of extended-spectrum $\beta$-lactamases (ESBLs) and ESBL-producing microorganisms. Clin. Microbiol. Infect. 2001, 7, 597-608.

2. Pitout, J.D.D.; Laupland, K.B. Extended-spectrum $\beta$-lactamase-producing enterobacteriaceae, an emerging public health concern. Lancet Infect. Dis. 2007, 8, 159-166.

3. Ahmad, I.; Aqil, F. In vitro efficacy of bioactive extracts of 15 medicinal plants against ES $\beta$ L-producing multidrug-resistant enteric bacteria. Microbiol. Res. 2007, 162, 264-275.

4. Lai, P.K.; Roy, J. Antimicrobial and chemopreventive properties of herbs and spices. Curr. Med. Chem. 2004, 11, 1451-1460.

5. Stavri, M.; Piddock, L.J.; Gibbons, S. Bacterial efflux pump inhibitors from natural sources. J. Antimicrob. Chemother. 2007, 59, 1247-1260.

6. Jiangsu New Medical College. Bai-qu-cai Chelidonium majus L. In Dictionary of Chinese Materia Medica; Shanghai Scientific Technical Press: Shanghai, China, 1977; Volume 1, pp. 726-727.

7. Colombo, M.L.; Bosisio, E. Pharmacological activities of Chelidonium majus L. (Papaveraceae). Pharmacol. Res. 1996, 33, 127-134.

8. Gibbons, S. Anti-staphylococcal plant natural products. Nat. Prod. Rep. 2004, 21, 263-277.

9. Zuo, G.Y.; Meng, F.Y.; Hao, X.Y.; Zhang, Y.L.; Wang, G.C.; Xu, G.L. Antibacterial Alkaloids from Chelidonium majus Linn (Papaveraceae) against clinical isolates of methicillin-resistant Staphylococcus aureus. J. Pharm. Pharmaceut. Sci. 2008, 11, 90-94.

10. Meng, F.Y.; Zuo, G.Y.; Hao, X.Y.; Wang, G.C.; Xiao, H.T.; Zhang, J.Q.; Xu, G.L. Antifungal activity of the benzo[c]phenanthridine alkaloids from Chelidonium majus Linn against resistant clinical yeast isolates. J. Ethnopharmacol. 2009, 125, 494-496.

11. Clinical and Laboratory Standards Institute. Performance Standards for Antimicrobial Disk Susceptibility Tests. Approved Standard; CLSI: Wayne, PA, USA, 2006; M2-A9. 
12. Clinical and Laboratory Standards Institute. Performance Standards for Antimicrobial Susceptibility Testing-17th Informational Supplement. Approved Standard; CLSI: Wayne, PA, USA, 2007; M100-S17.

13. Farmer, J.J., III. Enterobacteriaceae, Introduction, Identification. In Manual of Clinical Microbiology, 7th Ed.; Murray, P.R., Baron, E.J., Pfaller, M.A., Tenover, F.C., Yolken, R.H., Eds.; American Society of Microbiology: Washington, DC, USA, 1999; pp. 442-458.

14. Cho, K.M.; Yoo, I.D.; Kim, W.G. 8-Hydroxydihydrochelerythrine, 8-hydroxydihydroSanguinarine with a potent acetylcholinesterase inhibitory activity from Chelidonium majus L. Biol. Pharm. Bull. 2006, 29, 2317-2320.

15. Navarro, V.; Delgado, G. Two antimicrobial alkaloids from Bocconia arborea. J. Ethnopharmacol. 1999, 66, 223-226.

16. Okoli, A.S.; Okeke, M.I.; Iroegbu, C.U.; Ebo, P.U. Antibacterial activity of Harungana madagascariensis leaf extracts. Phytother. Res. 2002, 16, 174-179.

17. Clinical and Laboratory Standards Institute. Methods for Dilution Antimicrobial Susceptibility Tests for Bacteria that Grow Aerobically, 7th Edition; Approved Standard; CLSI: Wayne, PA, USA, 2006; M7-A7.

Sample Availability: Samples of the compounds 1-4 are available from the authors.

(C) 2011 by the authors; licensee MDPI, Basel, Switzerland. This article is an open access article distributed under the terms and conditions of the Creative Commons Attribution license (http://creativecommons.org/licenses/by/3.0/). 